\title{
A América Portuguesa sob as luzes do scanner: arquivos, reprodução e manipulação digital da cartografia histórica
}

\section{Amália Cristovão dos Santos}

RESUMO: Nas últimas décadas, a manipulação e o compartilhamento de cartografias do passado e a produção de cartografias históricas têm ganhado novos contornos em função dos desenvolvimentos na área da computação. Essas novas ou incrementadas possibilidades podem influenciar também as metodologias das pesquisas que mobilizam tais fontes ou produtos. No entanto, a feitura de novos mapas ou o processamento dos antigos por meio de programas GIS são inócuos quando não se imbricam adequadamente nos objetivos do trabalho acadêmico. No presente artigo, apresentaremos um conjunto de produções recentes, referentes principalmente à história colonial, que utilizam as ferramentas da informática de maneiras variadas para a reprodução, análise e criação de mapas. Esses trabalhos serão examinados por suas propostas individuais, mas principalmente por suas relações com os debates contemporâneos de redefinição da história da cartografia. Por meio da construção de uma sistematização inicial que permite distinguir as pesquisas analisadas de acordo com as formas como se articulam ou fazem uso de recursos tecnológicos, defenderemos as formas de associação entre a informática e a construção de conhecimento histórico que priorizam o uso da tecnologia como método intrinsecamente relacionado às questões e aos objetos de estudo.

PALAVRAS-CHAVE: Cartografia histórica. Programas GIS. Análise espacial. História colonial. América portuguesa.

ABSTRACT: Over the last decades, manipulating or sharing maps from the past and producing historical cartography have considerably changed in face of computational developments. Such new and improved possibilities may also influence the methodology in researches that deal with these documents or products. However, simply applying this technology can be innocuous when it does not properly integrates with the purposes of an academic investigation. In this paper, we present a recent published selection of studies, mainly regarding colonial history, in which tools of informatics were used in an array of ways, from reproducing to analyzing and creating maps. Aside from their particular arguments, these researches will be primarily examined on their relations with contemporary debates surrounding the redefinitions of the field of history of
1. Professora Mestre da Escola da Cidade. Doutoranda da Faculdade de Arquitetura e Urbanismo (FAUUSP) da Universidade de São Paulo (USP) e bolsista Fapesp. E-mail: <amaliasantos@ gmail.com.>. 
2. Uma reflexão contemporânea sobre a cartografia como documento histórico não pode deixar de referenciar os debates construídos pela Escola dos Annales, especificamente no que diz respeito à ressignificação das fontes de pesquisa. Para ampliar essa discussão, ver o volume organizado por um de seus historiadores de mais extensa produção, Jacques Le Goff (2005). Para um exame dos fundamentos e decorrências da sobredita Escola, ver obra organizada por Fernando Novais e Rogerio Forastieri Silva (2011). cartography. Proposing a preliminary classification that arranges studies according to their usage of computer resources, we advocate in favor of the ones in which technology is intrinsically related to problems and matters of historical analyzes.

KEYWORDS: Historical cartography. GIS software. Spatial analysis. Colonial history. Portuguese America.

Apresentação das premissas e do recorte proposto

De todas as fontes documentais usadas em pesquisas históricas, é seguro dizer que a mais afetada pelos desenvolvimentos tecnológicos das últimas décadas foi a cartografia. De um lado, as transformações no campo da informática facilitaram os processos de reprodução, divulgação e manipulação de mapas, o que permitiu que mais pesquisadores e pesquisadoras tivessem acesso a essas fontes e favoreceu tanto os trabalhos cujo objeto é o mapa como artefato quanto aqueles que recorrem aos mapas como depositórios de informação ou de debates específicos. Em paralelo, os programas de vetorização e georreferenciamento foram introduzidos como ferramentas para os estudos históricos, beneficiando as pesquisas que tomam o espaço como dado central, articulado ou não a outros objetos de estudo.

Não obstante o caráter recente da questão que ora procuramos cercar nas reflexões que seguem, que coloca certa urgência no exame aqui encetado, pode-se afirmar que essas análises são ainda propícias enquanto contribuições ao amplo debate sobre o caráter das fontes de pesquisa, suas variedades e especificidades, tal como proposto desde os primeiros desenvolvimentos da chamada Escola dos Annales. ${ }^{2}$ As aproximações entre a história e as pesquisas em arqueologia, antropologia, sociologia e geografia e a criação e o fortalecimento de campos como a história das mentalidades, do imaginário e a micro-história foram movimentos a um só tempo motivados por e motivadores de profundas revisões no caráter das fontes documentais. Destaca-se nesse processo a aproximação com a geografia humana ou, nas palavras de Jacques Le Goff, "a busca simultânea do espaço e do tempo" (LE GOFF, 2011 , p. 131).

O consciente afastamento em relação à história política pôs em xeque a preponderância das fontes produzidas no escopo das administrações e dos espaços oficiais, colocando em questão também e principalmente a quase exclusividade da documentação escrita como fundamento para o trabalho de historiadoras e historiadores (LE GOFF, 2011 , p. 128-176). Le Goff, em texto replicado frequentemente, destaca a relação entre documentação histórica e palavra escrita:

documento que, para a escola histórica positivista do fim do século XIX e do início do século XX, será o fundamento do fato histórico, ainda que resulte da escolha, de uma decisão do historiador, parece apresentar-se por si mesmo como prova histórica. [...] Além do mais, afirma-se essencialmente como um testemunho escrito. (LE GOFF, 2005, p. 536). 
É apenas com a perda de força da história positivista - defensora dos documentos como fatos históricos e do texto como documento primordial, senão exclusivo - que o autor vê surgir o debate metodológico acerca do que é constituída a história e, portanto, suas fontes. Em excertos de Lucien Febvre e Marc Bloch da década de 1940, Le Goff circunscreve a então mudança de paradigma com relação ao fazer historiográfico: não o obscurecimento do documento, mas o reconhecimento do documento como vestígio humano e, assim, não limitado aos registros escritos (LE GOFF, 2005, p. 539-540).

Contudo, essa ampliação no entendimento das fontes é apenas um passo no que o autor intitula "revolução documental" (LE GOFF, 2005, p. 541), que se traduz na alteração dos objetos de pesquisa - de grandes homens e acontecimentos pontuais para massas, coletividades e a "longa duração" - e na caudalosa ampliação numérica das fontes - engendrando o uso de bancos de dados e a seriação de fontes quantitativas. Em grande medida, essas possibilidades são proporcionadas justamente pelo desenvolvimento dos sistemas computacionais, associados à identificação de conjuntos documentais produzidos regularmente. Ainda assim, Le Goff ressalta que a computação ou a existência de fontes com qualidades específicas não devem ser os aspectos norteadores das pesquisas históricas:

Porque a história quantitativa não é nem uma revolução puramente tecnológica, nem a consequência de uma emergência do número na história. Não é imposta nem pelo computador nem pelo passado. Como observa Glénisson, no século XIX, ao princípio era o documento; hoje, ao princípio é o problema. (LE GOFF, 2005, p. 542).

Ainda que não esteja referindo-se especificamente a mapas e plantas, podemos destacar os escritos de Ulpiano Bezerra de Meneses como sínteses sistemáticas sobre as fontes visuais e os métodos historiográficos, tendo em mente, antes de mais nada, sua afirmação de que "Os artefatos, por exemplo, são não apenas produtos, mas vetores de relações sociais" (MENESES, 1994, p. 12). Aprofundando-se e encorajando um redirecionamento do olhar de historiadoras e historiadores, o autor explora também a historicidade da visualidade (MENESES, 2003) e objetos específicos, como a fotografia (MENESES, 2002).

De forma bastante semelhante, John Brian Harley, pesquisador exaustivo da história da cartografia e precocemente falecido, apresenta-nos uma guinada substancial no entendimento do mapa como fonte da pesquisa histórica ao elaborar - em repetidos textos, com focos variados - a ideia da cartografia como ação humana, em oposição à noção de mapa como reflexo ou mera representação do existente. Podemos traçar essa mudança desde o uso de expressões como "mapmaking" ou "mapping", que sugerem o mapeamento como objeto de análise -e não o mapa em si (HARLEY, 1989, p. 4-5).

Tal conceituação implica consequências significativas para o entendimento do mapa e de sua inserção na pesquisa histórica. Se a cartografia é um produto humano, as questões centrais de sua análise devem ser as questões 
3. "Mapas são tão convincentes a esse respeito porque as regras da sociedade e as regras da medição reforçam-se mutuamente numa mesma imagem" (tradução nossa).

4. "À medida que adota métodos computadorizados $\mathrm{e}$ Sistemas de Informações Geográficas, a retórica cientificista dos produtores de mapas torna-se mais acentuada" (tradução nossa). humanas, portanto sociais. Nessa equação, as oposições comuns usadas na leitura de mapas - "certo" e "errado", "preciso" e "impreciso", "objetivo" e "subjetivo" deixam de ser relevantes enquanto valor absoluto. Dando continuidade às proposições conceituais de Harley, nota-se que, a partir do momento em que se reconhece a condição humana do mapeamento e de seus produtos, entram em cena categorias tais como "interesse", "intenção", "disputa" e "conflito". Ou seja, o mapa deixa de ser entendido como um produto automático e passa a ganhar os contornos das sociedades nas quais é produzido. A hierarquia, as cores, os símbolos, as espessuras, as transparências e todas as demais configurações visuais adotadas simultaneamente baseiam-se e constroem o mundo social: "Why maps can be so convincing in this respect is that the rules of society and the rules of measurement are mutually reinforcing in the same image" (HARLEY, 1989, p. 6). ${ }^{3}$

Essas consequências são de especial interesse na reflexão ora proposta, já que a informática oferta, antes de mais nada, o aumento da precisão como um de seus principais benefícios em relação à cartografia manuscrita ou mesmo impressa por chapas metálicas. O reforço do discurso científico, para Harley, tenderia a acentuar a ideia de que mapas rigorosamente construídos seriam neutros, uma vez que se informariam apenas por critérios técnicos. Em suas palavras: "As they embrace computer-assisted methods and Geographical Information Systems, the scientistic rhetoric of map makers is becoming more strident" (HARLEY, 1989, p. 2). ${ }^{4}$

Portanto, a ampliação das fontes como documentos e a introdução da computação como parte do método de pesquisa são questões articuladas no decorrer dos debates historiográficos recentes - algo que ganha corpo quando direcionamos o olhar para a instrumentalização da informática no tratamento com fontes cartográficas. O que se pode apreender do conjunto de tais considerações é que muito foi proposto, mas ainda há poucos trabalhos que, de fato, colocam em prática ou dominam a operacionalização dos novos métodos de estudo, pesquisa e mobilização de fontes imagéticas, bem como - e talvez especialmente - no que tange à relação dessa documentação com as interfaces digitais.

Não podemos deixar de sinalizar que essas discussões têm pouco menos de quarenta anos de desenvolvimento. Segundo o historiador Jeremy Black,

Na década de 1980, potentes computadores desktop estavam tornando prontamente disponível a visualização rotineira de dados na tela, e o primeiro protótipo de um atlas eletrônico foi desenvolvido no Canadá em 1982. [...] Em 1989, o MundoCart/CD, o mapa do mundo digital em CR-ROM, estava disponível comercialmente. (BLACK, 2005, p. 39).

Ainda que sejam debates recentes, é igualmente notável a existência de lacunas no contexto brasileiro, em relação à produção estrangeira - destacadamente inglesa e norte-americana.

A própria obra supracitada de Black foi publicada originalmente em 1997, em língua inglesa, e apenas teve tradução para o português em 2005, ou seja, quase dez anos depois. No que diz respeito ao tema central deste artigo, a 
saber, os desenvolvimentos tecnológicos, esse período de tempo é amplo o suficiente para tornar obsoletas várias conclusões apontadas. ${ }^{5}$ Em bibliotecas das universidades brasileiras, é notável a ausência de traduções e mesmo originais das obras de teóricos essenciais às análises que encampamos, tais como Arthur Robinson, David Woodward, Denis Wood, Matthew Edney e o próprio Harley, o que limita sua permeabilidade nos debates nacionais.

Destacamos ainda o peso da produção de cartografia histórica nas análises desses autores estrangeiros sobre o uso de recursos da informática: por exemplo, os chamados "atlas históricos", reconstituições espaciais de guerras, movimentos de ocupação ou disputas de fronteiras, ocupam posição central no capítulo da obra de Black que circunscreve especificamente tal desenvolvimento. Essa consideração nos parece relevante em função da inexpressividade dessa produção no Brasil, frente às significativas empreitadas comerciais e acadêmicas produzidas em outras nações. Por não haver produção semelhante no contexto brasileiro, é preciso prestar especial atenção na tomada desses textos como fontes para a discussão das pesquisas que aqui apresentamos, vencendo o ímpeto de construir analogias simplificadas.

Essas distinções e até inexistências tornam ainda mais premente a necessidade de reflexões sobre a produção mais recente, buscando criar diálogos entre esses trabalhos e as discussões provenientes de outros países e contextos, tanto por seus conteúdos quanto por seu embasamento conceitual. Partindo do uso dessas fontes visuais - fotografias, pinturas, desenhos, mapas e outros - como documentos históricos em oposição a seu caráter ilustrativo, entendemos que também as novas formas de manipulação da cartografia devem ser utilizadas como possibilidades de reflexão sobre o território e não apenas como formas gráficas de representação de informações históricas no espaço - tal como ocorre na produção dos "atlas históricos", que muitas vezes são vistos como naturalizações de conflitos e disputas do passado.

$\bigcirc$ processo de análise, mapeamento e espacialização de dados históricos, portanto, não deve apenas complementar a investigação ou sobrepor-se a ela, e sim fazer parte da argumentação da pesquisa. É o que procuraremos mostrar no presente artigo, tendo como recorte vertentes recentes da pesquisa histórica principalmente sobre a América portuguesa, campo especialmente profícuo para nossa análise, uma vez que era destacadamente importante para as empreitadas coloniais impor seus sistemas de controle e administração nos novos territórios a serem conquistados. Em texto direcionado especificamente ao exame da relação entre cartografia e poder, Harley (1988) aponta para o interesse específico na investigação desses períodos. Segundo o autor,

Maps are never value-free images; [...] they are not in themselves either true or false. Both in the selectivity of their content and in their signs and styles of representation maps are a way of conceiving, articulating, and structuring the human world which is biased towards, promoted by, and exerts influence upon particular sets of social relations. By accepting such premises it becomes easier to see how appropriate they are to manipulation by the powerful in society. (HARLEY, 1988, p. 278). ${ }^{\circ}$
5. É o caso, por exemplo, das considerações acerca da ampliação da difusão de mapas e dados em formato digital. Entre 1997 e 2005 , a disponibilidade de internet aumentou territorial, quantitativa e qualitativamente em boa parte do globo, tornando pouco significativas as menções ao potencial do uso de CD-ROM como forma de compartilhamento das produções. Ainda que o autor tivesse previsto essas mudanças, suas consequências e desdobramentos criaram atualmente configurações de natureza distinta das então existentes, que alteram o panorama apresentado (BLACK, 2005, p. 404-405).

6. "Mapas jamais são livres de valores; [...] eles não são, por si sós, verdadeiros ou falsos. Tanto na seletividade de seu conteúdo quanto nos signos e estilos de representação, mapas são formas de conceber, articular e estruturar o mundo humano de maneira a enviesar, promover e influenciar relações sociais específicas. Ao aceitar essas premissas, passa a ser fácil ver o quanto os mapas são apropriados para a manipulação feita pelos poderosos da sociedade" (tradução nossa). 
7. É notável ainda que essa lógica de dominação não se esgotou com o fim da colonização e a formação de nações independentes na América do Sul. A título de exemplo, podemos nos remeter especificamente aos processos de ocupação e uso da província paulista, ao longo do oitocentos, e posteriormente do estado de São Paulo, até meados do século XX. Durante esse período, é seguro dizer que suas elites cafeicultoras deram continuidade ao movimento de configuração de seu território por meio de, entre outros dispositivos, a formulação de uma imagem particular de sua área, em que não havia vestígios das populações indígenas e seu modo de vida, cristalizada nos mapas provinciais e estatais. Segundo o geógrafo Antonio Carlos Robert Moraes, "A imagem da terra a ocupar é bastante cara às classes dominantes [no Brasil], a população sendo vista como um instrumento desse processo. A visão do 'espaço a se ganhar' é recorrente, do colonizador lusitano que se defronta com uma natureza estranha ao fazendeiro paulista que 'conquista' as terras do Oeste" (MORAES, 2002, p. 98).

No processo exato de que trata o autor, destacamos ainda a importância do caráter "técnico" dos mapas - e outras formas de descrição do espaço e de suas atividades - como forma de legitimar o projeto ali contido (HARLEY, 1988, p. 107).

8. "Exploradores e missionários portugueses que tinham pouco conhecimento de uma área específica localizada além da costa poderiam, de qualquer forma, projetar uma expansão continental por meio da evocação do sertão" (tradução nossa).

9. "[...] ao não incluir qualquer referência ao sertão ou outro grupo indígena - em outras palavras, ao evitar sinais e símbolos do desconhecido -, mapas como o
Os movimentos de expansão imperialista, desde as Grandes Navegações, são contextos nos quais o poder simbólico mostrou-se indispensável. $\bigcirc$ desmonte das formas locais e nativas de representação do espaço e de experiência territorial, com a subsequente imposição de modelos trazidos pelas metrópoles - mesmo que esses processos tenham resultado em hibridismos, e não em desaparecimentos completos -, era uma das maneiras de dominação a que os colonizadores sistematicamente recorriam. Como expõe Harley (1988, p. 279), o poder simbólico é frequentemente o mais presente e incidente na cartografia. A categorização em termos portugueses ou espanhóis e a criação de representações imagéticas dos territórios coloniais marcavam os espaços a serem incorporados aos impérios ibéricos, criando as justificativas e o imaginário que impulsionavam as ações de conquista.?

A indispensabilidade do mapeamento e da construção de representações e definições territoriais para as empreitadas colonizadoras portuguesas pode ser apreendida por meio das reflexões de Rex P. Nielson, com formação em literatura comparada, que explora o "sertão" como conceito estratégico desse movimento imperialista. Em suas palavras, "Portuguese explorers and missionaries who had little knowledge of a particular landscape beyond the coast could nevertheless project continental expanse by invoking the sertão" (NIELSON, 2014, p. 8). ${ }^{8} \bigcirc$ autor propõe, pois, que essa nomenclatura assinalava o domínio simbólico e, mesmo indicando desconhecimento, incorporava esse espaço ao território colonial português.

Nielson reconhece uma profusão do uso da denominação "sertão" nos mapas setecentistas da América portuguesa - frequentemente associada à presença indígena - e, desse momento em diante, o termo cai em desuso sendo substituído por "província" ou outra referência igualmente próxima da ordenação colonizadora (NIELSON, 2014, p. 14-15). Segundo o autor, a ausência dessa e de outras indicações de ocupação nativa na cartografia derivada das disputas e tratados de definição de fronteiras do século XVIII relacionar-se-ia à necessidade de comprovação de domínio efetivo do território:

[...] by not including any reference to the sertão or any other indigenous group - i.e., by avoiding the signs and symbols of the unknown - maps like the Mapa das Cortes [1749] authoritatively claimed the area of Brazil as espaço ocidentalizado, that is, as Portuguese territory ready to be exploited. (NIELSON, 2014, p. 16). ${ }^{9}$

À parte do uso dessa terminologia, em sua análise cartográfica, Nielson identifica as linhas de rumos dos primeiros mapas da América - que homogeneamente cortam a totalidade desses desenhos - como os elementos gráficos que operariam a sobredita incorporação simbólica desse espaço ao território ibérico (NIELSON, 2014, p. 12). Essas evidências vão ao encontro das considerações de Harley sobre o poder e a cartografia, ressaltando o quão imperativo é o exame cuidadoso do uso e da produção de mapas nos estudos históricos desse período. 
Além da aproximação do recorte cronológico geral, os trabalhos aqui referenciados são quase exclusivamente artigos escritos na última década ou pouco mais do que isso, tendo em vista o caráter de novidade - em termos de tempo decorrido - dos ditos desenvolvimentos tecnológicos e das reflexões sobre suas possibilidades e implicações. Não se trata de um mero apanhado randômico de exemplos e possibilidades de uso nem de um levantamento exaustivo e total dessa produção, mas do encadeamento de metodologias e temáticas de pesquisa, com o intuito de apontar caminhos que nos parecem ter maior ou menor pertinência para a inserção da computação na pesquisa histórica. Trata-se, assim, de uma avaliação da produção contemporânea, baseada em um pequeno recorte desse conjunto, orientado pelo interesse em delimitar especificamente o debate sobre os potenciais de construção histórica da cartografia criada ou analisada por meio de recursos computacionais. ${ }^{10}$

Tomaremos adiante: empreitadas de armazenamento e disponibilização de arquivos cartográficos; pesquisas que mobilizam mapas do passado como fonte, analisando-os com auxílio de recursos de informática; e trabalhos de produção de cartografia histórica a partir de outros mapas ou documentos variados. Levando a cabo as considerações supracitadas de Le Goff, Harley e Meneses - e outros escritos a serem mencionados -, podemos afirmar que a seleção de referências para este artigo circunscreve estudos que demonstram a necessidade de priorização da problemática de pesquisa como gerenciadora do uso das ferramentas computacionais, e não o contrário.

texto estrutura-se em três partes centrais - além de introdução e síntese final. No primeiro item, trataremos dos trabalhos que tomam o mapa como objeto de estudo, seja nas questões acerca de sua confecção original e circulação, seja no compartilhamento e alterações atualmente possíveis. A seguir, a segunda parte apresenta a aplicação dos programas computacionais à análise espacial histórica, focando nos meios de articulação entre conhecimentos técnicos e históricos. Com o objetivo de discorrer mais detidamente sobre as metodologias que inserem a tecnologia como meio de reflexão e argumentação da pesquisa, elencamos dois estudos em história colonial, analisados no terceiro item. ${ }^{11}$ Vale reforçar a intenção de propor a seguir uma sistematização possível para as reflexões indicadas devidamente inseridas no panorama corrente de reavaliação das fontes, campos e objetos históricos -, a partir da qual seja possível contribuir com a leitura desses e de outros trabalhos produzidos recentemente no campo da história, mas que de forma alguma se pretende definitiva.

objeto mapa: análises, reprodução e alcance

Mapas e fotos aéreas são materiais cuja acessibilidade ainda possui restrições, mesmo para pesquisa acadêmica. $\bigcirc$ acervo cartográfico do Arquivo Histórico do Itamaraty, no Rio de Janeiro (RJ), por exemplo, continua protegido por
Mapa das Cortes [1749] reivindicavam autoritariamente o espaço do Brasil como espaço ocidentalizado, ou seja, como território português pronto para ser explorado" (tradução nossa).

10. Parece-nos importante ressaltar que se trata de proposta de sistematização inicial: outras análises poderiam ser feitas tomando os mesmos estudos selecionados, bem como outros trabalhos poderiam compor nosso arcabouço referencial. Acreditamos, no entanto, que o escopo mobilizado possibilita com clareza realizar a investigação lançada.

11. No capítulo "GIS and History”, Anne Kelly Knowles propõe categorização comparável à que ora empreendemos. Note-se, entretanto, que sua forma de distinção entre obras e pesquisas baseia-se nos conteúdos abordados por tais trabalhos: usos históricos da terra e o desenvolvimento de economias no território; visualização de paisagens do passado e suas transformações ao longo do tempo; e construção de infraestruturas de armazenamento que permitam compartilhar e disponibilizar mapas. Além disso, as considerações da autora sobre as necessárias problematizações acerca da ideia do mapa como representação do real ou como veículo da verdade são inexpressivas em suas análises dos trabalhos que enumera como exemplares. Knowles faz uso indiscriminado de termos como "technically" (tecnicamente) como indicação de neutralidade e atribui à cartografia norte-americana a característica de "precisão", sem colocar em questão os vieses implícitos nessas construções. Como veremos adiante, os debates recentes sobre cartografia e história da cartografia têm sido especialmente atentos a essas e outras distinções (KNOWLES, 2008). 
12. A digitalização refere-se aos procedimentos fotográficos - feitos com câmeras ou scanners - que transformam os mapas em arquivos de imagem. Já a vetorização é o processo de "redesenho" total ou parcial dos mapas, resultando em documentos vetoriais, ou seja, formados por pontos, linhas e preenchimentos, que podem ser alterados individualmente sem a manipulação do conteúdo total. Os formatos finais de ambas são editáveis e podem ser usados como bases em programas computacionais, mas apresentam limitações diferentes, sendo adequados para tipos diversos de análises e produtos.

13. Disponíveis em: <http://www.google.com/earth/> e <https://www.google.com/maps/>. Acesso em: 25 jun. 2014.

14. Destacamos a relevância da produção de Iris Kantor em pesquisas que tomam determinadas cartografias como objetos de estudo. Mesmo sem relação com o uso de recursos tecnológicos, essas pesquisas acrescentam profundidade à participação da historiadora nos projetos de compartilhamento de documentos cartográficos, uma vez que apontam interesses específicos. Dentre seus trabalhos, são temas notáveis a disponibilidade dos mapas para diversos públicos $\mathrm{e}$ seus usos em circuitos fechados. Ver seus trabalhos individuais (KANTOR, 2009, 2010; GARCIA; KANTOR, 2011; KANTOR; THOMAS, 2014).

15. A BNRJ disponibiliza seu próprio acervo, enquanto a Biblioteca Digital reproduz o conjunto de mapas que faziam parte da coleção do Banco Santos e encontram-se sob custódia do Instituto de Estudos Brasileiros (IEB-USP). Disponíveis em: <http://bndigital.bn.br/> questões estratégicas e diplomáticas, iá que parte do conjunto são os mapas usados para definir as fronteiras nacionais em negociações diplomáticas durante o século XX. No entanto, é inegável que as plataformas virtuais e as técnicas de digitalização e vetorização lançaram bases para o favorecimento da divulgação desses documentos. ${ }^{12}$ A criação do Google Earth e do Google Maps ${ }^{13}$ representa a um só tempo um impulso e um sintoma do processo de aumento da veiculação de informações geográficas para o público geral.

Para as pesquisas históricas, isso significou de pronto a ampliação do acesso a esse material por meio da disponibilização das reproduções digitais dos desenhos em sites e portais. Essa ação, que pode parecer apenas um simples procedimento técnico, compreende as mesmas etapas da formação de qualquer acervo físico. Ou seja, são imprescindíveis os mesmos métodos de pesquisa e catalogação que são implementados na constituição das coleções de arquivos e museus históricos.

Em artigo sobre a criação da Biblioteca Digital de Cartografia Histórica, vemos de forma bem delineada uma das preocupações centrais acerca da ampla disponibilização das coleções cartográficas:

Se, por um lado, essa circunstância favorece a circulação de informações graças ao acesso às imagens cartográficas antigas, por outro, apenas a reprodução digital não propicia necessariamente uma apreensão acurada dos mesmos mapas. Por essa razão, concebemos a Biblioteca Digital de Cartografia Histórica da Universidade de São Paulo, procurando não só ampliar os recursos de contextualização histórica e pesquisa cartobibliográfica, mas também facilitar o rastreamento das imagens em outros sites especializados. Tais recursos pretendem reinserir as peças cartográficas em universos sociais mais amplos, reconstituindo seus contextos de produção, circulação e consumo. (KANTOR et al., 2013, p. 135). ${ }^{14}$

Podemos dizer que existem duas características de formação dos acervos digitais disponíveis atualmente: a digitalização de acervos preexistentes e os processos colaborativos, que adotam parâmetros para a seleção de material, mas podem ser alimentados continuamente por vários usuários. Cada acervo disponibiliza seu conteúdo em arquivos digitais de diferentes formatos, de acordo com o nível de manipulação e análise proposto.

primeiro caso - digitalização de arquivos existentes - tem se tornado comum no Brasil e no exterior. Destacamos como expoentes os catálogos eletrônicos da Biblioteca Nacional do Rio de Janeiro (BNRJ) e a Biblioteca Digital de Cartografia Histórica da USP. ${ }^{15}$ Ambas permitem que o pesquisador visualize e obtenha os mapas em diferentes formatos de imagem, podendo realizar manipulações e alterações a partir das demandas de seu próprio trabalho. Cada item é acompanhado de apontamentos bibliográficos e informações relevantes sobre sua feitura e circulação.

Em sua narrativa sobre a mudança de paradigma operada por Arthur Robinson e David Woodward na definição da cartografia como campo disciplinar e posteriormente da história da cartografia, Matthew Edney enumera três grupos 
inter-relacionados de agentes produtores de estudos históricos sobre cartografia na abordagem tradicional dessas pesquisas, a saber: geógrafos e historiadores; bibliotecários e arquivistas; e vendedores e colecionadores de mapas. $\bigcirc$ segundo conjunto, de acordo com o autor, empreenderia o trabalho de atrair pesquisadores em potencial, por meio da organização e divulgação do conteúdo dos arquivos cartográficos. No cumprimento dessas atividades, essas pessoas teriam também realizado um grande número de trabalhos sobre os mapas que buscavam catalogar, produzindo material consistente sobre esses documentos (EDNEY, 2005, p. 15-16).

Ainda hoje, é possível identificar a participação de responsáveis por grandes acervos em congressos e encontros acadêmicos, reconhecendo a relevância de seus textos. Devido à importância desses agentes no panorama construído por Edney, cabe-nos apontar que não há muitos paralelos no caso das instituições brasileiras. Ao contrário, é mais comum o acúmulo das funções de coordenação de arquivos (físicos ou virtuais) com a pesquisa acadêmica sobre os mesmos, e o quadro funcional participa de forma limitada, em relação aos contextos norte-americano e europeu, da construção de conhecimento científico.

No mundo que se pode chamar de ibero-americano, o interesse pelas cartografias do passado esteve grandemente relacionado ao ensejo original de que é fruto a maioria dos mapas que ainda hoje tomamos como fontes de pesquisa. Ou seja, a expansão dos impérios europeus, em larga medida operacionalizada pela produção de mapeamentos e projeções do Novo Mundo, foi também a motivação primeira desse campo de estudo, por longo período. De acordo com Héctor Mendoza Vargas e João Carlos Garcia,

Entre os países ibero-americanos a História da Cartografia tem alguma tradição junto dos eruditos, dos militares e dos diplomatas: os velhos mapas espanhóis ou portugueses fazem parte do imaginário historiográfico ligado aos episódios da expansão geográfica europeia da Época Moderna [.... . (VARGAS; GARCIA, 2007, p. 2).

colecionismo e as temáticas relacionadas à evolução técnica da cartografia e à definição de fronteiras foram as forças principais na constituição de arquivos nas nações formadas quando da independência das antigas colônias: "No início do século XIX, os governos latino-americanos lançaram-se na produção, impressão e edição de mapas nacionais, que figuravam os seus vastos territórios, então bastante desconhecidos para as elites políticas, concentradas nas capitais" (VARGAS; GARCIA, 2007, p. 4). Tanto os mapas reunidos como os motivos das catalogações e inventariações advinham, pois, das intenções modernizadores e econômicas de Estados e importantes figuras particulares.

Vargas e Garcia não deixam de apontar a relevância dos recursos tecnológicos recentemente disponibilizados para a ampliação do acesso aos acervos que contêm esses conjuntos documentais. Além disso, os autores ressaltam também as mudanças ocorridas em função das aproximações entre os campos da cartografia, da geografia e da história, que alteraram as análises de mapas antigos e as significações da cartografia em geral (VARGAS; GARCIA, 2007, p. 3-4). e <http://www.cartografiahistorica.usp.br/>. Acesso em: 24 jun. 2014. 
16. Disponível em: <http:// lhs.unb.br/biblioatlas/Início>. Acesso em: 26 jun. 2014.

17. Disponível em: <http:// maps.nypl.org/warper/>. Acesso em: 24 jun. 2014.

18. A palavra "warp", do inglês, significa "deformar" ou "torcer" e refere-se aqui ao procedimento de ajuste dos mapas.

19. Esse tipo de procedimento, comum em geoprocessamento, é usado não apenas na comparação de mapas de datas diferentes, mas também na compatibilização da cartografia com fotos aéreas ou imagens de satélite.

20. Os pontos de controle são as representações de feições que têm pouca ou nenhuma probabilidade de terem mudado de lugar ao longo do tempo, tais como cruzamentos de vias ou edificações pouco modificadas, pontes, desenhos de rios e outras.

21. Essa forma de comparação pela sobreposição de mapas é chamada, no campo do geoprocessamento, de overlay.
O segundo caso de acervos digitais que ora apresentamos corresponde à criação de atlas virtuais formados a partir de um tema ou pesquisa - é o caso do Atlas Digital da América Lusa, ${ }^{16}$ desenvolvido pelo Laboratório de História Social da Universidade de Brasília (LSH-UnB). Além de cartografia do Brasil colonial, o Atlas contém o BiblioAtlas, uma espécie de enciclopédia, com mais de 3 mil artigos, até o momento, referentes às localidades e edificações representadas nos mapas. Usando o software I3GEO, criado pelo Ministério do Meio Ambiente, os usuários podem consultar o banco de dados resultante, cujas informações foram inseridas de forma colaborativa.

Unindo a digitalização de um acervo físico e a alimentação colaborativa, a Biblioteca Pública de Nova York (NYPL) ${ }^{17}$ - cujo acervo digital foi lançado a público em junho de 2016 - desenvolveu a ferramenta NYPL Map Warper, ${ }_{18}^{18}$ que possibilita aos usuários não apenas acessar o conteúdo, mas "retificar" os mapas digitalizados - ou "rectify", em inglês. Com isso, é possível ajustar os desenhos antigos às coordenadas dos mapas do presente, de forma que as informações da cartografia histórica possam ser localizadas nas representações que usamos atualmente e até mesmo encontradas no mundo físico.

Esse processo de georreferenciamento, ${ }^{19}$ como é chamado, é feito pela escolha de "pontos de controle" 20 - elementos representados tanto no mapa atual quanto no mapa histórico - para "distorcer" o desenho antigo, permitindo que todas as cartas de um determinado local com escalas compatíveis possam ser sobrepostas e analisadas comparativamente. ${ }^{21}$ À medida que os usuários realizam essa operação, os novos mapas - "retificados" - são também disponibilizados no site e podem ser usados por outras pessoas, já prontos para serem inseridos em programas computacionais de geoprocessamento.

O uso de mapas históricos como bases de informação e sua possível manipulação digital colocam-nos a importância da correta compreensão das características do mapa - solicitação, execução e divulgação. Sem esse estudo, a interpretação dos elementos presentes na cartografia fica prejudicada e até mesmo equivocada, correndo-se o risco da utilização dessa fonte como mera ilustração da pesquisa, em oposição à sua integração com as questões abordadas e os objetos de estudo. A ênfase nas possibilidades de criação a partir dos mapas carrega ainda o risco da naturalização das informações nele contidas e da sua forma de representação. Não podemos ignorar também que, nesses processos, são desenvolvidas novas normatizações da linguagem visual cartográfica, que devem ser igualmente problematizadas. Como ressalta Black (2005, p. 403), "De modo mais geral, o uso de computadores leva a uma medida de padronização na produção de mapas. Isso é, em parte, uma questão dos hardware e software disponíveis, que afetam questões de simbolização, escolha de cores e potencial cartográfico". Assim como para os mapas do passado, frequentemente objetos de análise, os padrões de representação das ferramentas digitais são produtos humanos, que devem ser assim entendidos e apreendidos. 
Desse modo, o trabalho com essa fonte deve partir de uma reflexão sobre o próprio material cartográfico. Identificamos "o problema da autoria dos mapas" como uma das vertentes desse estudo, uma vez que as "redes de colaboração", com "[os] cartógrafos, os gravadores, os ilustradores e, eventualmente, os editores" eram responsáveis pelas informações contidas - e suprimidas - nesses desenhos (KANTOR et al., 2013, p. 14).

Além da autoria e da circulação, o aspecto técnico é outra perspectiva de análise da cartografia como objeto, que qualifica - se não possibilita - seu uso como fonte de pesquisa. Segundo Beatriz Bueno, "Longe de serem uma reprodução fidedigna do real, mapas são representações". Por essa condição, é imprescindivel "interpretar os mapas elaborados pelos engenheiros militares portugueses setecentistas do ponto de vista da cultura material, circunscrevendo nossa atenção no seu processo de produção" (BUENO, 2004, p. 194).

Com esse objetivo, Bueno enumera as características das disciplinas tributárias da produção cartográfica do período colonial, a saber, geometria, astronomia, geografia e belas-artes, permitindo uma apreensão mais apurada desses mapas. A partir da análise da autora, podemos extrair uma gama de questões: as variações na forma de representação das localidades, por exemplo, significam diferentes níveis dentro da hierarquia oficial; os símbolos para cada tipo de árvore, por sua vez, indicam o interesse nos recursos naturais disponíveis para exploração econômica; os elementos presentes no mapa, naturais ou construídos, indicam o tipo de ocupação existente; e assim por diante (BUENO, 2004, p. 204, 202, $219-2211$.

De acordo com as proposições de John Brian Harley, o estudo dos tratados e do material de ensino dos agentes produtores de mapas é indispensável à compreensão da cartografia do passado e deve ser somado à análise de outro conjunto de regras que também incidem sobre o desenho desses produtos.

The question is, of course, historically specific: the rules of cartography vary in different societies. Here I refer particularly to two distinctive sets of rules that underlie and dominate the history of Western cartography since the seventeenth century. One set may be defined as governing the technical production of maps and are made explicit in the cartographic treatises and writings of the period. The other set relates to the cultural production of maps. These must be understood in a broader historical context than either scientific procedure or technique. (HARLEY, 1989 , p. 3-4). ${ }^{22}$

No Brasil colonial, a produção dos mapas servia a interesses de diversos setores envolvidos nos empreendimentos da expansão marítima - do que resultavam mapas com características e elementos distintos. Um dos objetivos da cartografia colonial era a comprovação da ocupação da terra, como forma de obter a posse legítima em negociações diplomáticas. Por essa razão, era necessário produzir mapas da colônia que contivessem denominações comprovadamente portuguesas para localidades e regiões em disputa com a Coroa espanhola.
22. "Obviamente a questão tem especificidades históricas: as regras da cartografia variam em diferentes sociedades. Aqui, refiro-me particularmente a dois conjuntos distintos de regras subjacentes e dominantes na história da cartografia ocidental desde o século XVII. Um dos conjuntos pode ser definido como dirigente da produção técnica de mapas e é explicitado pelos tratados cartográficos e demais escritos do período. O outro conjunto relaciona-se à produção cultural dos mapas. Esse deve ser entendido num contexto histórico mais amplo do que procedimentos científicos ou técnicas" (tradução nossa). 
23. Assim como Iris Kantor, Beatriz Bueno possui outras entradas na investigação histórica que privilegia os aspectos espaciais. Ver, a esse respeito, a pesquisa em que localiza dados da Décima Urbana de 1809, referentes a São Paulo, que permite a formulação de conclusões acerca das dinâmicas imobiliárias na cidade (2005); o trabalho recém-lançado no qual agrega novos dados a essas localidades (2016); e o artigo sobre a expansão da ocupação colonial no sertão da América portuguesa (2009). Os dois primeiros artigos mencionados serão objeto de nossa análise a seguir.

24. No excerto, trata-se de reflexão sobre a produção de mapas, que, entretanto, ecoa na análise dos incrementos na disponibilização de documentação em meios virtuais (BLACK, 2005, p. 410).
A Academia Real passou a solicitar às autoridades coloniais e aos colonos o envio de descrições geográficas, memórias históricas e documentação comprobatória da ocupação efetiva de todos os domínios lusitanos. Parte dessa documentação, colhida in loco, serviu, posteriormente, à preparação do Mapa das Cortes (1749), encomendado por Alexandre de Gusmão para as negociações com a Espanha em 1748-1749. A assinatura do Tratado de Madrid (1750) marca uma inflexão importante no tratamento dessas questões. Desde então, além do estabelecimento da fronteira "natural" (rios e picos das serras), os demarcadores procuraram fixar uma toponímia que traduzisse o processo de ocupação efetiva do território. O nome das povoações e aldeamentos missionários passou a ser um elemento-chave na definição das fronteiras entre os impérios ibéricos. (KANTOR, 2009, p. 44).

que esses trabalhos de Bueno e Kantor - entre outros - nos mostram é que os avanços na informática, que ampliam as possibilidades de acesso aos mapas, são de pouco ou nenhum valor dentro das pesquisas históricas, se não forem acompanhados da ampliação de conhecimentos sobre esse material. ${ }^{23} \mathrm{Em}$ poucas palavras, a análise e a interpretação de uma fonte cartográfica não podem ser feitas apenas por questões externas a ela - questões provenientes da pesquisa em curso -, e sim devem levar em conta suas circunstâncias originais. Jeremy Black aborda a insuficiência do uso de recursos tecnológicos, sobre o que diz:

A tecnologia só pode ir até aí. Se um dos propósitos da cartografia histórica é fixar generalizações precisamente no espaço, então ainda acontece que as habilidades de pesquisa histórica são frequentemente necessárias para fazê-lo, antes que qualquer processo de mapeamento possa se realizar. ${ }^{24}$

Dito isso, passaremos à avaliação das formas de utilização de programas computacionais para o processamento das fontes cartográficas.

\section{A incorporação dos programas GIS}

A história da criação e propagação das tecnologias GIS - sigla em inglês para Sistema de Informações Geográficas - engloba um pequeno conjunto de países, entidades governamentais, universidades e pessoas. Essa variedade, ainda que pequena, indica a impossibilidade da construção de uma narrativa totalmente linear desses acontecimentos, dada a ocorrência de sobreposições e simultaneidades. Além disso, parte desses agentes não possui registros acessíveis de suas atividades, o que cria lacunas no encadeamento dos eventos que resultaram na atual disponibilidade de softwares relativamente simples, que podem ser usados em praticamente qualquer computador pessoal.

De toda forma, é possível distinguir quatro estágios de desenvolvimento, a saber:

The first, or pioneering age, extended from the early 1960s to about 1975; in this, individual personalities were of critical importance in determining what was achieved. The second pha- 
se, approximately from 1973 until the early 1980s, saw a regularization of experiment and practice within and fostered by national agencies; local experiment and action continued untrammeled and duplication of effort was common. The third phase, running from about 1982 until the late 1980s, was that of commercial dominance. The fourth (and current) phase is one of user dominance [...]. (COPPOCK; RHIND, 1991, p. 21)..25

Ainda que estivessem tratando do início dos anos 1990, os autores encerram seu texto com uma bem-sucedida previsão acerca da hegemonia que o GIS alcançaria, em questão de pouco mais de uma década, considerando que os estágios de "desenvolvimento" de tal tecnologia haviam chegado ao fim e, assim, iniciava-se então o momento de ênfase em seu "uso": "This is the end of the beginning of GIS"26 (COPPOCK; RHIND, 1991, p. 40).

Coppock e Rhind arriscam uma hipótese para a preponderância do Canadá e dos Estados Unidos como locais de desenvolvimento das tecnologias geográficas de que tratam. Para os autores, a vastidão de seus territórios é razão fértil para o incremento das iniciativas de monitoração e controle espacial, o que teria direcionado recursos e esforços nesse sentido (COPPOCK; RHIND, 1991). Notemos ainda que as agências governamentais são destaque entre os agentes envolvidos nessas ações. A lista de organizações centrais nos desenvolvimentos dos sistemas de informação geográfica - especialmente a abundância dos usos militares e administrativos - dá-nos uma ideia dos interesses e usos inicialmente previstos para tal tecnologia, o que reforça o questionamento de John Brian Harley sobre o uso de programas GIS sem a devida problematização.

Are the mechanics of the new technology so preoccupying that cartographers have lost interest in the "meaning" of what they represent? And in its social consequences? And in the evidence that maps themselves can be said to embody a social structure? If material efficiency is allowed to dominate the design and construction of maps, we can see why the ethical issues tend to pass unnoticed. The technology of Geographic Information Systems (GIS) becomes the message, not just the new "form" or medium of our knowledge. The crisis of representation is now the crisis of the machine. This is not the first time this has happened in the history of cartography. As Roger Chartier puts it, form produces meaning: "Both the manipulation of the reader and the appropriation of a text's meaning always depend on its material forms, which are invested with an 'expressive Function'." At present it is one material form - the all persuasive technology - that is increasingly dominating the discourse of cartography. (HARLEY, 1990 apud OLIVEIRA, 2014, p. 155). ${ }^{27}$

É notável, por retrospectivas tais como a que ora apresentamos, que o desenvolvimento desses programas e métodos computacionais se associa inquestionavelmente aos interesses econômicos e de administração estatal - de forma não muito distante daquela identificada na produção da cartografia das conquistas dos impérios ibéricos. Outro paralelismo pode ser também estabelecido: o lugar de autoridade assumido pelos mapas portugueses e espanhóis, nos processos de subjugação das populações americanas, é comparável em alguma medida com o grau de persuasão - tomando as palavras de Harley - atingido pelas modernas tecnologias de análise espacial.
25. "A primeira, ou fase pioneira, estende-se do início dos anos 1960 até cerca de 1975; nela, personalidades individuais tiveram importância central na determinação do que era atingido. A segunda fase, aproximadamente de 1973 até o começo da década de 1980, assistiu à regularização dos experimentos e das práticas dentro das agências nacionais ou promovidos por elas; ações e experiências locais continuaram de forma irrestrita, e era comum a repetição de esforços. A terceira fase, de 1982 até o final da década de 1980 , foi de predomínio comercial. A quarta (e atual) fase é de predomínio do usuário [...]" (tradução nossa).

26. "Este é o final do começo do GIS" (tradução nossa)

27. "Os mecanismos da nova tecnologia demandam tanta atenção que os cartógrafos perderam o interesse no 'significado' do que representam? E em suas consequências sociais? E nas evidências de que os próprios mapas podem personificar uma estrutura social? Se é permitido que a eficiência material domine o design e a criação de mapas, podemos perceber por que as questões éticas tendem a passar despercebidas. A tecnologia de Sistemas de Informação Geográfica (SIG) passa a ser a mensagem, e não apenas a nova 'forma' ou meio de nosso conhecimento. A crise da representação passa a ser a crise da máquina. Não é a primeira vez que isso aconteceu na história da cartografia. Como afirma Roger Chartier, forma produz significado: 'Tanto a manipulação do leitor quanto a apropriação do significado de um texto dependem sempre de seu formato material, que está investido com um 'Função de expressão'. No presente, uma única forma material - a persuasiva tecnologia - 
está crescentemente dominando o discurso cartográfico" (tradução nossa).

28. Ainda que não sejam os únicos estudos a fazerem uso da análise cartográfica associada à pesquisa histórica, citaremos como exemplares os trabalhos de Roberta Delson, sobre os planos urbanizadores da Coroa portuguesa no Brasil e a consequente criação sistemática de vilas e cidades (DELSON, 1997), e de Nestor Goulart Reis Filho, que explora a formação do que o autor chama de "rede urbana" colonial, entre o início da colonização e as primeiras décadas do século XVIII (REIS FILHO, 1968).
A expressão "Geographic Information Systems", da qual se origina a sigla GIS, foi usada apenas na década de 1980. Contudo, a automação na cartografia e 0 trabalho com bancos de dados capazes de localizar informações nos eixos $x, y$ e z são ações anteriores a essa data. Mais ainda, a combinação de estudos acerca do desenvolvimento territorial e de fontes cartográficas não foi criada a partir dos avanços na área da informática. A análise de mapas é um recurso presente na historiografia brasileira e a ela se devem obras de destaque sobre a urbanização e ocupação do território no período colonial. ${ }^{28}$ No entanto, os benefícios das ferramentas computacionais são inegáveis: destacadamente, o aumento da precisão, a maior rapidez nas operações, as possibilidades virtualmente infindáveis de correções e a facilidade de divulgação e compartilhamento dos produtos.

Diversos tipos de software podem ser usados nesses procedimentos programas de manipulação de imagens, de criação de planilhas e bancos de dados, de vetorização, entre outros -, mas a reunião dessas operações de forma integrada é encontrada apenas nos programas GIS. Nesses programas, informações de tipos diversos são associadas à localização geográfica em que ocorrem e a alteração de qualquer dado resulta em mudança imediata no mapa e vice-versa, garantindo a integração entre um atributo e sua representação cartográfica.

Além dessa integração, os programas GIS permitem a "visualização simultânea" de um conjunto de dados de uma forma que pode ser considerada de outro modo impossível sem o mapa. Ou seja, um grupo de informações encontrado de forma descritiva - por exemplo, documentação censitária, alfandegária ou fazendária - pode ser apreendido em sua totalidade com o uso de uma forma de representação que contém essas informações na íntegra - o mapa georreferenciado. Além de inserir todos os dados em um mesmo meio, ao associar diretamente as informações ao espaço e a outros tipos de informação, a visualização simultânea pode trazer à tona novas conclusões extraídas de uma mesma fonte.

A computadorização de dados, mesmo antes de sua disponibilização de maneira georreferenciada, trouxe uma transformação fundante na manipulação de grandes volumes de informação, como destaca Jeremy Black:

O computador tornou possível mapear materiais que até então não haviam sido mapeáveis sem enorme esforço. Era especialmente valioso para a análise de materiais sociais e econômicos. Eles tinham uma forma mais volumosa do que os tópicos padrão de mapeamento político - fronteiras e guerras - e grande parte deles exigia análise prévia se tivesse de ser mapeável. (BLACK, 2005, p. 402).

que se observa nessa mudança é a ampliação do campo de possibilidades da pesquisa histórica, que pode assim concretizar de forma mais adequada a problematização da história positivista e balizada por fontes e acontecimentos oficiais - ou oficializados -, tal como preconizava a Escola dos Annales.

Para que essas vantagens tenham efeito real sobre a pesquisa - e não sejam subutilizadas ou apenas ilustrativas - é preciso conhecer propriamente as 
características das fontes utilizadas, as possibilidades técnicas da informática e a melhor combinação dessas dentro dos objetivos de estudo. No artigo "A cartografia digital como ferramenta para a cartografia histórica" (CINTRA, 2009) encontramos um bom apanhado sobre as informações que devem ser conhecidas para o estabelecimento da melhor relação entre fonte e instrumental.

trabalho trata especificamente das variações de software e das formas de adequação da cartografia utilizada. Os pontos levantados pelo autor são: transposição do desenho físico para o meio digital; reconhecimento dos dados básicos sobre o mapa, a saber, escala, projeção e meridiano de origem; definição do programa a ser usado na análise, a partir dos atributos do documento original e das intenções do pesquisador; elaboração de material quantitativo em planilhas e tabelas associadas à cartografia; e uso de camadas - ou layers, em inglês - para comparar informações de naturezas ou períodos diferentes.

No mesmo sentido, Marcos Ferreira e Marta Felicia Ferreira descrevem o processo de reconstrução da paisagem de Jaboticabal em 1927, pela criação do que denominam "cartas-imagem históricas [que] mostram, sobre a camada da paisagem atual, elementos da paisagem pretérita contendo objetos socialmente construídos no passado" (FERREIRA; FERREIRA, 2011 , p. 2). Por meio da sobreposição do mapa histórico à cartografia atual e da criação de zonas de probabilidade de presença dos elementos representados no desenho antigo, foi possível obter "a localização de objetos que ainda permanecem na atualidade, os que já foram extintos, e os que permanecem apenas na forma de resquícios" (FERREIRA; FERREIRA, 2011 , p. 1).

Nota-se que uma das preocupações centrais dos autores é a adequação da fonte histórica às possibilidades do software usado, sem o questionamento das informações contidas no mapa de 1927. ${ }^{29}$ Em outras palavras, a carta-imagem histórica produzida no processo descrito traz os mesmos elementos da fonte cartográfica, sendo que essa foi composta com metodologia e intenção próprias, diversas daquelas do produto da pesquisa atual. A paisagem "reconstruída", portanto, abstém-se de questionar a paisagem construída e a paisagem representada.

É importante ressaltar que, para os pesquisadores do campo da história, - grau de aprofundamento sobre cada um dos aspectos apresentados por esses autores é bastante variável. Contudo, o comum distanciamento dos estudiosos de Humanidades em relação aos conhecimentos de informática e programação é suprimido a contento pelas parcerias realizadas nos laboratórios acadêmicos e centros de estudos. ${ }^{30}$ Além disso, os vínculos com pesquisadores das áreas de geografia e história econômica também podem ser benéficos para os estudos que se valem da cartografia histórica como fonte.

A retroalimentação entre os campos de conhecimento - ou a transdisciplinaridade - é indispensável para que a pesquisa histórica possa se beneficiar da computação. ${ }^{31}$ No artigo supracitado, Cintra (2009) enumera apenas questões técnicas referentes às fontes cartográficas. Em trabalho do mesmo com a
29. São inúmeros os exemplares de textos e pesquisas históricas que se dedicaram ao estudo da trajetória de cartógrafos, engenheiros e de seus produtos, ou seja, da feitura dos mapas. São esses trabalhos que possibilitam, antes ou independentemente da utilização de recursos computacionais, a problematização dos elementos representados em dada cartografia, seja pelo aspecto gráfico ou pelo conteúdo. Além de menções já presentes neste artigo, citamos aqui, a título de referência: os artigos de André Ferrand de Almeida (2009a, 2009b), que descrevem os processos de produção do Mapa Geográfico de América Meridional (1775) e da cartografia feita por José Gonçalves da Fonseca em expedição da metade do setecentos; a investigação de Júnia Ferreira Furtado (2009) sobre a participação do cartógrafo José Joaquim da Rocha nas movimentações da Inconfidência Mineira, em fins do século XVIII; e os trabalhos recentes de José Rogério Beier, que circundam aspectos da produção do $\mathrm{Ma}$ ppa Chorographico da Provincia de São Paulo e da biografia de seu autor, o engenheiro Daniel Pedro Müller, reunidos principalmente em sua dissertação de mestrado (2015), orientada por Iris Kantor.

\footnotetext{
30. Como exemplo, mencionamos as próprias atividades da Biblioteca Digital de Cartografia Histórica da USP, cuja criação contou com o auxílio do Centro de Informática de São Carlos (USP), para o desenvolvimento do banco de dados, da organização interna e do site público (KANTOR et al., 2011, p. 136).
}

31. Especificamente no que concerne à cartografia como fonte ou como produção da pesquisa histórica, fica patente, pelos textos já mencionados anteriormente (HARLEY, 1989; EDNEY, 
2005), a indispensabilidade da comunicação e apropriação circunstanciada entre os campos de trabalho envolvidos, tais como história, geografia, cartografia, informática, estatística, arquivística e outros. historiadora Júnia Ferreira Furtado (2011), no entanto, é possível observar a articulação entre a cartografia digital e o estudo histórico. Por meio de ferramentas de análise cartográfica, os autores são capazes de identificar pontos de convergência entre diferentes mapas da região amazônica, demonstrando uma sequência de apropriações que influenciaram a definição final das fronteiras da área.

Uma das questões que ainda mobilizam a historiografia são as fontes cartográficas utilizadas para a feitura do Mapa das Cortes, citadas imprecisamente por Alexandre de Gusmão. É objetivo também deste artigo apontar as proximidades entre esse mapa e a Carte de l'Amérique Méridionale, verificando se esta última serviu de fonte para o primeiro, a despeito da proibição de Alexandre de Gusmão de mostrar o mapa de D'Anville aos espanhóis. Embora se desconheça esse fato até então, ele efetivamente ocorreu e pode-se ter certeza disso ao se observar a correspondência entre os dois documentos na configuração das bacias dos rios Rupunuwini, Essequebé e Negro, que constam da Folha 1 da Carte de l'Amérique Méridionale, e o mesmo trecho do Mapa das Cortes. Essa forma de representação da hidrografia da região, com a inclusão do lago Amacu e a supressão do Parima, foi conferida por D'Anville, na Carte de l'Amérique Méridionale, graças a um mapa desenhado por um prussiano chamado Horstman, que realizou uma viagem desde Caiena, utilizando a hidrografia amazônica. Esse manuscrito the foi fornecido pelo savant francês Charles Marie de La Condamine, que conheceu Horstman em Belém, e serviu para D'Anville propor uma quase conexão (um varadouro) entre o Amazonas, o Negro e o Essequebé. (CINTRA; FURTADO, 201 1, p. 276-277).

O texto deixa explícita a convergência entre as possibilidades técnicas e as questões historiográficas:

Assim, o presente trabalho, graças a recursos da cartografia digital e da estatística, compara os três mapas para efeito de verificar concordâncias e dissonâncias entre eles no estabelecimento de diversas coordenadas geográficas da região norte do Brasil. No caso da Carte de l'Amérique Méridionale, as conclusões alcançadas ainda serão cotejadas com os escritos de D'Anville sobre o processo de sua produção. (CINTRA; FURTADO, 2011 , p. 279).

A formação de pesquisadoras e pesquisadores capazes de compreender e operar instrumentos computacionais tem se tornado mais comum no panorama acadêmico brasileiro, não apenas por meio de parcerias, mas também pelo envolvimento direto em investigações e grupos que investem nessas metodologias. Nesse sentido, é notável a participação de alunos e alunas da área de arquitetura, que regularmente já contam com espaço em sua grade curricular para o desenvolvimento dessas habilidades, destacadamente na utilização de programas variados.

As pesquisas de Beatriz Bueno na escala urbana são exemplo preciso disso. Em artigo de 2005, a historiadora publicizava os resultados da espacialização dos dados do imposto predial de São Paulo coletado em 1809, georreferenciando os dados desse documento nos lotes da cidade (BUENO, 2005). Cerca de uma década depois, em 2016, a autora apresenta-nos nova 
pesquisa - que contou com uma participação ainda maior de bolsistas e estudantes -, em que recorre a novas fontes censitárias, edilícias, cartográficas e outras, de modo a expandir seu recorte cronológico e agregar novos dados ao espaço em análise (BUENO, 2016). Após constatar, no primeiro desses textos, a existência do que pode ser denominado como "mercado imobiliário" no alvorecer do século XIX, Bueno aprofunda-se nessa problemática, comprovando a predominância do investimento privado na produção imobiliária urbana e seu expressivo crescimento ao longo do oitocentos. $\bigcirc$ arco criado pelos dois trabalhos é paralelo à verticalização da pesquisadora na geo-história braudeliana e na aplicação dos GIS para criação de cartografia histórica.

É forçoso destacar que o mencionado artigo de 2016 faz parte de um dossiê da Revista do Instituto de Estudos Brasileiros, cuja segunda parte ainda será publicada, reunindo textos sobre São Paulo e Lyon, que têm em comum a orientação metodológica e teórica ora sucintamente citada. $\bigcirc$ conjunto de trabalhos deriva de uma pareceria que envolve instituições das duas cidades, pertencentes aos campos de história, arquitetura e geografia (OLIVA et al., 2016).

Outros trabalhos dessa edição elucidam de forma mais explícita o viés teórico que mobilizam, circunscrevendo com mais precaução o papel das ferramentas digitais. É o que se vê no trecho: "As elaborações que seguem se inserem nos estudos históricos do mundo urbano, dando essencialidade à questão espacial. Para tal, um recurso teórico de proa disponível é a geo-história aplicada às cidades. $\bigcirc$ olhar geo-histórico descreve e interpreta os períodos históricos de uma cidade tendo como centro a organização espacial produzida. Desse modo, condições espaciais pretéritas são apreendidas como um "estudo geográfico de processos históricos". (FONSECA et al., 2016, p. 133-134).

$\bigcirc$ que buscamos discutir nesse item são as potenciais lacunas criadas quando o uso dos programas computacionais se descola da pesquisa histórica e segue apenas ou majoritariamente as possibilidades técnicas das ferramentas existentes. É preciso buscar paridade entre os diferentes conhecimentos envolvidos, sem perder de vista o objetivo da pesquisa, em vez da simples aplicação de um método ou processo a uma fonte histórica. Nesse sentido, a formação adequada para essas investigações e propostas multidisciplinares passa a ser definidora da qualidade de suas conclusões. $\bigcirc$ conhecimento mais apurado desses recursos configura um campo de maior integração entre os métodos e as hipóteses, sobre o que nos debruçaremos no item que segue.

A informática, entremeando a questão e o método

A aproximação entre as pesquisas históricas e as novas tecnologias da informática deveu-se destacadamente à possibilidade de tabular e organizar espacialmente extensos conjuntos de dados, antes apenas legíveis linear e sequencialmente (KNOWLES, 2008, p. 2). Fontes tais como recenseamentos 
32. Não nos parece pertinente ao escopo deste artigo aprofundar-nos nessas definições, bastando-nos apontar sucintamente que, na análise de Knowles, a geo-história e as demais investidas da Escola dos $A n$ nales trabalham com o espaço e a materialidade como agentes históricos - em oposição ao entendimento então corrente de que seriam produtos ou reflexos de uma dada sociedade ou cultura. Já a história espacial seria um termo que permite amplo enquadramento, relacionando-se às experiências humanas no espaço de modo geral. A história visual, por sua vez, contemplaria ações que concedem mais relevância às imagens que aos textos, produzindo acervos, frequentemente virtuais, a partir dos quais o público pode estabelecer as relações e conclusões que lhe parecerem pertinentes. (KNOWLES, 2008, p. 4-5).

33. "Como frequentemente acontece na pesquisa geográfica, a observação de distribuições espaciais (o que o historiador Bernard Bailyn chamou de 'o uso meramente ilustrativo de GIS') pode resultar em novas hipóteses e interpretações de pesquisa e prover layers de dados para análises espaciais mais complexas" (tradução nossa). populacionais, documentos de natalidade, matrimônio ou óbito, registros de cobranças de impostos e outras cujos conteúdos podem ser facilmente quantificados e localizados num dado território têm suas análises especialmente favorecidas pela computação.

A utilização de tais ferramentas, no entanto, enfrenta obstáculos no campo da história devido à necessidade de ao menos algum conhecimento mais aprofundado sobre o funcionamento dos softwares e à falta de familiaridade de historiadores e historiadoras com o uso e manipulação de imagens, habilidades pouco presentes em sua formação acadêmica. Além disso, a esse respeito, são notáveis as divisões epistemológicas que podemos chamar de tradicionais entre geografia e história - ainda que o desenrolar do século XX, com a fundamentação da geografia humana e da Escola dos Annales, tenha assistido ao fortalecimento da interlocução entre esses campos.

No capítulo introdutório da obra Placing History IKNOWLES, 2008, p. 1-25), a geógrafa Anne Kelly Knowles apresenta algumas das relações possíveis entre a pesquisa histórica e o referencial geográfico. São elas: a geo-história braudeliana; a história espacial (spatial history, em inglês, expressão cunhada por Paul Carter), que contém ainda as experiências do que a autora denomina como história visual ou história digital (respectivamente traduções de visual history e digital history); e o GIS histórico (Historical GIS, nos termos originais), que articula elementos dos outros subcampos. ${ }^{32}$ Em exame dessas relações e suas potencialidades, a autora afirma que

As often happens in geographical research, seeing geographical distributions (what historian Bernard Bailyn once called "the merely illustrative" use of GIS) can generate new research hypotheses and interpretations and provide layers of data for more complex spatial analysis. ${ }^{33}$ (KNOWLES, 2008, p. 10).

Longe de ser apenas um adendo à pesquisa, claro está que a informática pode ser também uma forma de reflexão plenamente inserida no percurso investigativo. Para examinar essa possibilidade, citamos o trabalho de reconstituição dos caminhos da Estrada Real (ANTUNES; CARVALHO; UMBELINO, 2010), baseado na cartografia que representava essas rotas - e complementado por outras fontes -, cujo objetivo final era o reconhecimento das estradas e região como patrimônio histórico e cultural.

Esse trabalho tem paralelos com a metodologia de construção das cartas-imagem históricas - citada anteriormente -, principalmente no que tange aos procedimentos de localização das informações presentes na cartografia histórica. No entanto, o estudo não busca unicamente identificar elementos históricos na paisagem do presente, e sim reinserir esses remanescentes no território atual, sob a perspectiva de que a sua formação é intrinsecamente relacionada ao processo histórico.

Os autores partem da utilização dos Sistemas de Informação Geográfica, de modo geral, como forma de monitoramento e subsídio para 
tomadas de decisão, e chegam à sua aplicação nas pesquisas históricas. Dentro desse processo, há um breve trecho que demonstra a consciência da necessidade do domínio dos aspectos técnicos envolvidos nessa operação, como apontado anteriormente, a partir de Cintra:

A preocupação existente durante a escolha do mapa foi a de trabalhar sobre um documento que pudesse transmitir com clareza as informações existentes e que fosse dotado, também, de registros relacionados às operações cartográficas de orientação, projeção e expressão gráfica. (ANTUNES; CARVALHO; UMBELINO, 2010, p. 66).

O estudo destaca-se por ter um objetivo claro, que gere os aspectos técnicos do trabalho - nesse caso, uma intenção utilitária, mas não mais relevante e prática que as hipóteses de uma pesquisa acadêmica. Novamente, trazemos aqui a referência das discussões sobre a produção cartográfica menos ou nada relacionada aos debates acadêmicos. É o caso dos já mencionados atlas históricos comerciais ou dos mapas rodoviários norte-americanos, usados por John Brian Harley como exemplo de sua teoria da desconstrução da cartografia, especificamente na parte derivada da interpretação de conceitos criados por Jacques Derrida (HARLEY, 1989, p. 8-9). Disso, apreende-se que a definição clara dos objetivos de pesquisa, acadêmica ou não, é um fator que qualifica o uso das ferramentas computacionais na análise de cartografia histórica.

A fim de apontar uma forma de extrapolação ainda maior das possibilidades da informática na pesquisa histórica, tomamos o trabalho de Angelo Alves Carrara e Rafael Martins de Oliveira Laguardia, sobre os "registros de terras de meados da década de 1850 no Brasil - como fonte capaz de fornecer elementos consistentes para a análise do processo de ocupação e uso do solo" (CARRARA; LAGUARDIA, 2013 , p. 3). No artigo, os autores expõem a metodologia criada para reconstruir o tecido fundiário da antiga paróquia de Santo Antônio de Paraibuna (MG), a partir dos registros de terras - tornados obrigatórios pela Lei de Terras de 1850 -, tendo em vista a reconstituição da estrutura agrária da região. $\mathrm{Na}$ ausência de um mapa que representasse tais informações, criou-se uma metodologia para executar essa cartografia.

O que se vê nesse trabalho é um exemplo das aplicações da tecnologia GIS, tal como identificado por Jeremy Black: "[...] os métodos computadorizados oferecem novas abordagens para harmonizar diferentes fontes históricas, e o mapeamento é uma consequência possível" (BLACK, 2005, p. 393). Os pesquisadores fizeram uso de fontes descritivas para traçar informações espaciais, atribuindo aos dados dos registros um caráter geográfico. Os registros contam apenas com descrições dos terrenos, em que podem constar nome do proprietário, nome da propriedade, alguma referência de dimensões e propriedades vizinhas, como se vê no excerto a seguir:

Uma fazenda de cultura denominada Boa Vista sita neste distrito freguesia de Santo Antônio do Paraibuna que se compõe de uma sesmaria de terras medidas e demarcadas divide com 
34. O que é aqui chamado de "relação de vizinhança" corresponde ao conceito de topologia - tal como será apresentado a seguir, no mesmo item deste artigo e também se alinha à ideia de situação, "que permite conhecer um sítio [características locais] a partir da horizontalidade em relação à sua vizinhança, tendo como base propriedades como distância e contiguidade em relação a outros sítios. A situação nos parece [...] ser o conceito principal da análise espacial" (FERREIRA, 2006).

35. As denominações "principal" e "confrontante" vêm da documentação original. Note-se que nem sempre as propriedades confrontantes possuem registro próprio. as fazendas denominadas Fortaleza, Garajanga, São Lourenço, São Domingos, Cachoeira. Todas sitas neste mesmo distrito e freguesia acima declarados. Foi comprada a José Bastos Pinto e sua mulher dona Rosa como consta dos respectivos títulos. //José Antônio Henriques. (CARRARA; LAGUARDIA, 2013, p. 15).

Os dados constantes dos registros não são padronizados - fato que os pesquisadores atribuem às diferentes condições materiais de cada paróquia e às necessidades díspares de cada região no que diz respeito às disputas de posse e poder locais -, de modo que não podem ser simplesmente transpostos para uma base cartográfica atual.

O caráter local dos registros é expresso também na utilização de referências pouco precisas para a localização das propriedades, com o uso da vizinhança como a principal forma de definição dos limites dos terrenos. Essa aparente imprecisão não se constituía em problema jurídico naquele período, pois o reconhecimento de legitimidade dava-se justamente pela autenticação entre os proprietários:

[...] para efeito da divisão e demarcação de propriedades rurais, bastava que os diretamente envolvidos no processo reconhecessem a precisão dos elementos tomados como marcos, de maneira que ao final as partes estivessem todas "conciliadas quanto à maneira de dividir", nas palavras do juiz da paz responsável. (CARRARA; LAGUARDIA, 2013, p. 12).

Tomando a característica principal dos registros - a relação de vizinhança ${ }^{34}$ que é também um conceito central para o geoprocessamento -, os pesquisadores desenvolveram uma metodologia própria para construção cartográfica. Trata-se de um roteiro de precisão crescente do posicionamento e dimensionamento das propriedades, criado a partir da listagem de propriedades principais - aquelas que possuem registro - e confrontantes ${ }^{35}$ - aquelas que são mencionadas como vizinhas no registro das principais.

O roteiro conta com quatro etapas: (1) representação gráfica aleatória, que permite posicionar as confrontantes em relação à principal, seguida da representação informada pela declaração recíproca de vizinhança, que possibilita a correção das posições; (2) conversão das dimensões declaradas em metros quadrados, a fim de tornar as posições proporcionalmente corretas, com definição da forma geométrica da propriedade, a partir do número de confrontantes e das medidas de tamanho; (3) redistribuição referenciada, em que a geometria resultante da etapa anterior é ajustada à cartografia atual; e (4) inserção no mapa de todas as informações disponíveis sobre as propriedades e proprietários por meio de layers que contêm dados não padronizáveis, mas que podem ser úteis para futuras identificações e outros estudos a partir do mesmo material.

As etapas acima descritas baseiam-se nos conceitos de geoprocessamento comuns aos programas de GIS. A primeira característica que apontaremos é a topologia, ou seja, a descrição dos polígonos - no caso, as propriedades - à esquerda e à direita de cada arco - ou dos limites das propriedades - conectando 
um polígono ao outro. Vemos o uso da topologia marcadamente na configuração das dimensões proporcionais das propriedades. Segundo os autores,

É possível ainda em alguns casos alcançar e analisar as possibilidades de dimensões das propriedades pelo pressuposto do confinamento, isto é, conhecendo as medidas das propriedades vizinhas ou confrontantes chega-se a possibilidades de mensurar aproximadamente a propriedade confinada no espaço permitido pelas de seu entorno. ICARRARA; LAGUARDIA, 2013, p. 13).

A definição das formas de cada propriedade, por sua vez, é descrita em duas possibilidades. A primeira pode ser chamada de "manual", pois é feita pela distribuição da área da propriedade pela figura geométrica de número de arestas igual à quantidade de confrontantes mencionados. Ou seja, se o registro define cinco propriedades vizinhas, atribui-se à principal a geometria de um pentágono, como forma de aproximação inicial das descrições à realidade.

Já a segunda possibilidade baseia-se na criação de buffers - zonas de probabilidade, tais como no trabalho supracitado de Ferreira e Ferreira (2011) -, numa operação característica do geoprocessamento informatizado. Segundo consta, "As diferenças não parecem fundamentais e a segunda forma chega a ser mais prática e rápida de aplicação do que a primeira" (CARRARA; LAGUARDIA, 2013, p. 17).

$\mathrm{Na}$ terceira etapa do roteiro supracitado, ocorre a atribuição da geometria e dos dados à situação real, ou seja, "unir os aspectos geográficos às informações da estrutura fundiária construída e reconstruída pela sociedade". Nesse ponto, os pesquisadores recorrem especificamente ao uso de programas GIS, "para um melhor resultado e manejo das informações pela interface virtual" (CARRARA; LAGUARDIA, 2013, p. 17-18).

Os procedimentos apresentados acima, repetidos para cada registro, geram uma rotina que foi transformada num soffware específico, uma vez que a construção de mapas não é uma atividade desinteressada, e sim parte do processo de pesquisa e, portanto, não pode sempre ser cumprida a contento pelas ferramentas disponíveis. Carrara e Laguardia afirmam ainda que a conversão desse procedimento no Sistema de Espacialização de Propriedades por Vizinhança (SEPV) foi justificada pelo "incompleto auxílio dos programas de GIS para o trato da informação histórica" ICARRARA; LAGUARDIA, 2013 , p. 181.

Em resumo, os pesquisadores adotaram ferramentas computacionais como meio para a execução do processamento de suas fontes, produzindo uma forma de visualização que permitisse a apreensão espacial dos dados documentais, criando uma representação que estimulasse outras reflexões pouco concebíveis no formato original das fontes - e, por fim, ampliando os limites do instrumental técnico disponível, para que ele acompanhasse os questionamentos da pesquisa. 
36. Encontramos boas sínteses desses debates em artigos de Maria do Carmo Andrade Gomes (2004) e de Giseli Girardi (2000). No primeiro, a autora descortina a formação e recente revisão da história da cartografia como campo autônomo, desde o colecionismo relacionado às artes visuais até a tomada dos mapas e plantas como fontes de pesquisa, sobre as quais recai todo o questionamento e problematização devidos a qualquer outra documentação. No segundo, Girardi recorre à linguística e traz à tona a definição da cartografia enquanto disciplina e sua predisposição, intencional ou não, à criação de mitos referentes principalmente - mas não exclusivamente - ao território, tal como a própria ideia de fronteira. Em ambos os trabalhos são empreendidas competentes sistematizações das pesquisas, eventos e publicações de referência para os sobreditos temas.

37. No referido texto, Edney coloca em perspectiva a relação entre esses dois cartógrafos e a forma como alteraram a cartografia enquanto disciplina, partindo dessa prática para a criação de obras que redefiniriam a história da cartografia. Destacamos aqui como a nova conceituação do mapa e da atividade cartográfica foi fundante para o debate historiográfico - e não o contrário.

38. O autor baseia-se principalmente em conceitos construídos por Michel Foucault e Jacques Derrida para desenvolver uma guinada epistemológica na interpretação de mapas. Sobre os princípios iniciais dessa proposta, ver o já mencionado artigo de John Brian Harley (1989).

39. Trabalho interessante nessa direção é a pesquisa recentemente publicada de Jorge Pimentel Cintra
Conclusões e rumos

Feitas as considerações anteriores, vale lembrar a estória relatada por Emmanuel Le Roy Ladurie no capítulo "O historiador e o computador", inserido na coletânea Nova história em perspectiva, sobre o uso do computador para plotar dados acerca dos cortesãos de Guilherme II. A coleta e inserção de dados genealógicos e geográficos sobre essas pessoas, após ser tabulada na máquina, resultou na conclusão de que eram provenientes da região mesma em que se localizava a corte, ou seja, a resposta equivaleu à própria pergunta. "Essa anedota ilustra uma evidência: na história, como em outros campos, o que conta não é a máquina, mas sim o problema", diz o autor (LADURIE, 2011 , p. 207).

De forma consoante, o que podemos observar pela análise dos métodos utilizados nas pesquisas supracitadas é a indispensabilidade do diálogo afinado entre o objeto da pesquisa histórica - com suas fontes e hipóteses - e os conceitos e as ferramentas de análise espacial. Ou seja, a utilização desse cabedal teórico e instrumental por razões meramente estéticas ou tecnicistas é insignificante para os estudos históricos. Essa premissa fica clara nos trabalhos de caráter predominantemente subsidiário, tais como a configuração de catálogos eletrônicos de cartografia histórica, mas deve ser levada a cabo nos demais campos de pesquisa.

Tal questão ganha potência e refere-se ao próprio reexame recente acerca da cartografia enquanto disciplina e da história da cartografia. ${ }^{36} \mathrm{~A}$ manipulação de cartografia existente ou a construção de novas cartografias que remetam ao passado não podem ser empreendidas sem o questionamento da atividade de produção dos mapas - tal como aponta Matthew Edney, em artigo acerca das proposições de Arthur Robinson e David Woodward. ${ }^{37}$ Harley recorreu à filosofia e à linguística a fim de fundamentar o que denominou como desconstrução do mapa, um processo a ser levado a cabo pelas pesquisas históricas. ${ }^{38} \bigcirc$ argumento central desse debate é a já mencionada desmistificação do caráter de "precisão" dos mapas, que lhes dá propriedades irrevogáveis e incontrariáveis - exceto quando se prova a existência de falhas técnicas em seu desenho. ${ }^{39}$ Segundo o autor, "we [historians] often tend to work from the premise that mappers engage in an unquestionably 'scientific' or 'objective' form of knowledge creation" (HARLEY, 1989, p. 1).

Como vimos anteriormente, para Harley, essa compreensão do mapa como produto infalível tende a reforçar-se com a ampliação do acesso ao instrumental computacional, vendido como mais confiável, mais rápido e, portanto, mais preciso. Como forma de reinserir a cartografia na pesquisa histórica, o autor elabora a seguinte estratégia:

I shall specifically use a deconstructionist tactic to break the assumed link between reality and representation which has dominated cartographic thinking, has led it in the pathway of "normal science" since the Enlightenment, and has also provided a ready-made and "taken for 
granted" epistemology for the history of cartography. The objective is to suggest that an alternative epistemology, rooted in social theory rather than in scientific positivism, is more appropriate to the history of cartography. It will be shown that even "scientific" maps are a product not only of "the rules of the order of geometry and reason["] but also of the "norms and values of the order of social [...] tradition". Our task is to search for the social forces that have structured cartography and to locate the presence of power - and its effects - in all map knowledge. 40 (HARLEY, 1989, p. 2).

A temática do poder é de especial relevo para o debate acerca da cartografia tal como conduzido por Harley e seus colegas. $\bigcirc$ autor circunscreve especificamente a relação entre o mapeamento e a estratégia política:

This has become clear, for example, from a detailed study of cartography in prehistoric, ancient and medieval Europe, and the Mediterranean. Throughout the period, "mapmaking was one of the specialised [sic] intellectual weapons by which power could be gained, administered, given legitimacy, and codified". ${ }^{41}$ (HARLEY, 1988, p. 281 ).

No mesmo texto, Harley trata ainda das distorções intencionais, da escolha da geometria, das ilustrações ornamentais encontradas em variadas cartografias e dos ocultamentos contidos em certos desenhos, incluindo mapas e até plantas cadastrais - temas em nada desconhecidos das pesquisas acerca da América portuguesa, desde Jaime Cortesão. ${ }^{42}$ Do conjunto dessas análises, o geógrafo conclui que a pesquisa histórica sobre os mapas deve ser tomada como um exame dos seus discursos, em consonância com estudos sociológicos, crítica de arte e história da arte, mas sem perder de vista as peculiaridades de seus signos (HARLEY, 1988, p. 300).

Os mapas, no entender de Harley, são instrumentos de poder, cujas formas de produção e divulgação concentram-se nas mãos de elites - e há poucas maneiras de subverter essa característica. ${ }^{43}$ Novamente, sua preocupação com a informática reside no fato de que os desenvolvimentos e inovações das últimas décadas ampliaram o acesso e o alcance da cartografia sem, contudo, alterar os agentes sociais que detêm os conhecimentos e meios de produção de plantas, mapas e demais representações geográficas. ${ }^{44}$

Como se vê, a mera existência da informática ou seu uso não seriam suficientes como pontos de inflexão na discussão historiográfica. No final da década de 1990, até onde era possível observar, Jeremy Black afirmou que "A tecnologia oferece novas possibilidades de descrição, mas não está claro até que ponto isso está levando a mudanças no conteúdo". ${ }^{45}$ Posto de outra forma, mesmo com as transformações possibilitadas pelo novo instrumental, a metodologia da construção do conhecimento histórico não havia sido transformada em seu âmago.

$\bigcirc$ historiador Tiago Kramer de Oliveira ${ }^{46}$ identifica um conflito entre 0 uso das novas tecnologias na produção de cartografia histórica e os debates propostos pelos autores acima citados, uma vez que a criação de novos mapas não escaparia às críticas acerca do exercício de poder contido na cartografia -
(2013), na qual o engenheiro propõe um novo desenho para o mapa original das capitanias hereditárias da América portuguesa. A modificação apontada está no desenho das divisões ao norte do território, que, de acordo com o autor, teria sido equivocadamente interpretado nas fontes consultadas por Varnhagen e assim representado no mapa publicado em sua obra História Geral do Brasil. As conclusões de Cintra tratam mais expressamente da precisão do plano de divisões das terras recém-invadidas. Contudo, não podemos desconsiderar as eventuais possibilidades de redirecionamento do olhar sobre esse espaço a partir de uma nova representação, ou seja, de uma nova imagem desse território.

40. "Usarei especificamente a tática desconstrutivista para romper a presumida relação entre realidade e representação que tem dominado o pensamento cartográfico, conduzido-o ao caminho da 'ciência normal' desde o Iluminismo, criando uma epistemologia que é banalizada na história da cartografia. O objetivo é sugerir que uma epistemologia alternativa, baseada em teoria social e não em positivismo científico, é mais apropriada para a história da cartografia. Será mostrado que até mapas 'científicos' são produtos não apenas das 'regras da ordem da geometria e razão['] mas também das 'normas e valores da ordem da tradição [...] social'. Nossa tarefa é buscar as forças sociais que estruturaram a cartografia e localizar a presença do poder - e seus efeitos - em todo o conhecimento cartográfico" (grifos nossos, tradução nossa).

41. "Isso tem se tornado explícito, por exemplo, a partir de estudos detalhados de cartografias do Mediterrâneo e da Europa pré- 
-histórica, antiga e medieval. Ao longo desse período, 'mapeamento era uma das armas intelectuais especializadas por meio das quais era possível obter, administrar, legitimar e regulamentar o poder'" (tradução nossa).

42. Os estudos de Cortesão (2006), especialmente sua obra sobre o uso do mapa como recurso nas negociações do Tratado de Madrid, não pertencem ao recorte bibliográfico proposto neste artigo, porém é digno de nota o quanto sua questão central pode ser articulada à discussão proposta por Harley sobre a presença universal da retórica na cartografia. Segundo o autor, "There is nothing revolutionary in the idea that cartography in an art of persuasive communication" (HARLEY, 1989, p. 10), cuja tradução seria "Não há nada revolucionário na ideia de que cartografia é uma arte de comunicação persuasiva".

Na mesma linha, estão as produções recentes de Mario Clemente Ferreira (2007), Júnia Ferreira Furtado (2011) e Iris Kantor (2013), que abordam diferentes aspectos da relação entre diplomacia, cartografia e disputas territoriais.

A análise pautada na retórica encontra também desdobramentos nas pesquisas sobre a América portuguesa, como é o caso do trabalho de Cláudia Damasceno Fonseca (2010), no qual, inclusive, a autora dialoga diretamente com os estudos de Edward Lynam e John Brian Harley, na construção de seu exame sobre as vilas da capitania de Minas, na metade final do setecentos.

43. Vale aqui breve reflexão nossa: o poder contido e exercido pelos mapas, tal como advoga Harley, não nos parece inerente ao mapa em si, enquanto objeto, e sim potencial, ou seja, trata-se de algo que pode ser mobilizado em processos de divulga- qualquer cartografia. Segundo ele, os intelectuais da "Nova História da Cartografia [...] destacam a impossibilidade de pensar o mapa como detentor de informações objetivas e desinteressadas, algo que pode parecer óbvio, mas que, como vimos, é, senão ignorado, levado pouco em consideração por muitos pesquisadores" (OLIVEIRA, 2014, p. 156).

Entretanto, como esperamos ter sido possível vislumbrar nos trabalhos apresentados no decorrer deste artigo, as ferramentas computacionais especialmente a manipulação e produção de novas cartografias - podem permitir, entre outras coisas, dar voz a agentes sociais antes obscurecidos e construir novas histórias, assim como proposto pela Escola dos Annales - e pretendido por historiadoras e historiadores contemporâneos. Nessas pesquisas, o instrumental da informática submete-se firmemente a investigação e problematização históricas.

É o que se vê nas considerações finais de Carrara e Laguardia, ao tratarem do momento em que é finalizada a construção do mapa dos registros fundiários. Segundo os autores, uma vez feita a configuração espacial das terras da paróquia, "É aqui que começa de fato a análise do processo de uso e ocupação do solo" (CARRARA; LAGUARDIA, 2013, p. 20). Da mesma forma, Antunes, Carvalho e Umbelino afirmam que o uso de programas GIS para análise de cartografia histórica deve ser feito "integrando-o com aspectos teóricos, metodológicos e práticos [do estudo histórico]" (ANTUNES; CARVALHO; UMBELINO, 2010, p. 66, grifos nossos), ou seja, buscando articular a tecnologia aos interesses da pesquisa. Em outras palavras, os procedimentos de geoprocessamento de mapas históricos - que contêm em si discussões de escopo e método - têm valor central como instrumento de pesquisa e não sustentam interesse quando desassociados das questões abordadas, advindas da história e, portanto, ancoradas nos interesses e motivações do presente.

\section{REFERÊNCIAS}

ALMEIDA, André Ferrand de. O mapa geográfico de América Meridional, de Juan de la Cruz Cano y Olmedilla. Anais do Museu Paulista, São Paulo, v. 17, n. 2, p. 79-89, jul./dez. 2009a.

A viagem de José Gonçalves da Fonseca e a cartografia do rio Madeira (1749-1752). Anais do Museu Paulista, São Paulo, v. 17, n. 2, p. 215-235, jul./dez. 2009b.

ANTUNES, Américo; CARVALHO, Rodrigo; UMBELINO, Glauco. Reconstituição dos caminhos da Estrada Real através da cartografia histórica e do geoprocessamento. In: ENCONTRO NACIONAL DE ESTUDOS POPULACIONAIS, 17, 2010, Caxambu. Anais... Caxambu: Abep, 2010. 
BEIER, José Rogério. Artefatos de poder: Daniel Pedro Müller, a Assembleia Legislativa e a construção territorial da província de São Paulo (1835-1849). 2015. Dissertação (Mestrado) - Faculdade de Filosofia, Letras e Ciências Humanas da Universidade de São Paulo, São Paulo, 2015.

BLACK, Jeremy. Mapas e história: construindo imagens do passado. Bauru: Edusc, 2005.

BUENO, Beatriz Piccolotto Siqueira. Decifrando mapas: sobre o conceito de "território" e suas vinculações com a cartografia. Anais do Museu Paulista, São Paulo, v. 12, p. 193234, jan./dez. 2004.

. Tecido urbano e mercado imobiliário em São Paulo: metodologia de estudo com base na Décima Urbana de 1809. Anais do Museu Paulista, São Paulo, v. 13, n. 1, p. 59-97, jan./jun. 2005.

Dilatação dos confins: caminhos, vilas e cidades na formação da Capitania de São Paulo (1532-1822). Anais do Museu Paulista, São Paulo, v. 17, n. 2, p. 251-294, jul./dez. 2009.

Arqueologia da paisagem urbana: lógicas, ritmos e atores na construção do centro histórico de São Paulo (1809-1942). Revista do Instituto de Estudos Brasileiros, São Paulo, n. 64, p. 99-130, ago. 2016.

CARRARA, Angelo Alves; LAGUARDIA, Rafael Martins de Oliveira. Georreferenciamento e História Agrária: distribuição espacial das propriedades rurais a partir dos registros de terras de meados do século XIX. Castellón: Sociedad Española de Historia Agraria, 2013. Disponível em: <http://ideas.repec.org/p/seh/wpaper/1301.html>. Acesso em: 9 jun. 2014.

CINTRA, Jorge Pimentel. A cartografia digital como ferramenta para a cartografia histórica. In: SIMPÓSIO LUSO-BRASILEIRO DE CARTOGRAFIA HISTÓRICA, 3., 2009, Ouro Preto. Anais... Ouro Preto: Ufop, 2009.

Reconstruindo o mapa das Capitanias Hereditárias. Anais do Museu Paulista, São Paulo, v. 21, n. 2, p. 11-45, jul./dez. 2013.

; FURTADO, Júnia Ferreira. A Carte de l'Amérique Méridionale de Bourguignon D'Anville: eixo perspectivo de uma cartografia amazônica comparada. Revista Brasileira de História, São Paulo, v. 31, n. 62, p. 273-316, 2011.

COPPOCK, John Terence; RHIND, David William. The History of GIS. In: MAGUIRE, David; GOODCHILD, Michael Frank; RHIND, David William. (Ed.). Geographical Information Systems: Principles and Applications. New York: Wiley, 1991. p. 21-43. v. 1.

CORTESÃO, Jaime Zuzarte. Alexandre de Gusmão E o Tratado de Madrid. São Paulo: Imprensa Oficial; Fundação Alexandre de Gusmão, 2006. Tomos 1 e 2.

DAMASCENO, Claudia Fonseca. Retóricas cartográficas: as vilas e seus territórios nas Minas setecentistas. In: SIMPÓSIO IBEROAMERICANO DE HISTÓRIA DA CARTOGRAFIA - Agendas para História da Cartografia Iberoamericana, 3., 2010, São Paulo. Anais... São Paulo: 2010. ção, reprodução, manipulação ou subtração da cartografia existente. Entendemos, portanto, que um mapa não é si atribuído de poder, mas pode sê-lo por meio de ações humanas, de operacionalizações sociais. Nossas conclusões são colocadas aqui como proposições de aprofundamento do debate exposto, sem terem, contudo, intenção de descartá-lo.

44. É indispensável lembrar que essa afirmação foi feita em fins da década de 1980 . No entanto, parece-nos ainda válida e talvez até mais acentuada em seu conteúdo. Basta termos em mente a presença maciça e quase intransponível da empresa Google na produção e divulgação de mapas ou a limitada quantidade de nações possuidoras de satélites de fotografia e mapeamento da superfície terrestre.

45. A formulação acima refere-se à cartografia histórica, mas, em nosso entender, pode ser expandida para os outros campos em que os recursos tecnológicos e os mapas se encontram na pesquisa histórica (BLACK, 2005, p. 400).

46. Em artigo de 2014, Oliveira faz um breve balanço da utilização da cartografia nas pesquisas recentes sobre América portuguesa. As ferramentas digitais são também ponto focal de seu texto; no entanto, sua seleção é mais restrita, permitindo maior destaque para formulações próprias sobre os significados dos mapas, criando interlocuções com os autores que toma como referência. Valem destaque: sua aproximação com a fenomenologia de Henry Bergson - ressignificando a cartografia por meio da exploração de campos alheios a ela, assim como fez Harley -; a ideia do mapa como retórica dentro de um campo de disputa; e as proposições que elucidam as relações entre o imaginário e o material. (OLIVEIRA, 2014). 
DELSON, Roberta Marx. Novas vilas para o Brasil-Colônia: planejamento espacial e social no século XVIII. Brasília: Alva-Ciord, 1997.

EDNEY, Matthew. Putting "Cartography" into the History of Cartography: Arthur R. Robinson, David Woodward, and the Creation of a Discipline. Cartographic Perspectives, n. 51, p. 14-29, spring 2005.

FERREIRA, Marcos César. Considerações teórico-metodológicas sobre as origens e a inserção do sistema de informação geográfica na geografia. In: VITTE, Antonio Carlos. Contribuições à história e à epistemologia da geografia. Rio de Janeiro: Bertrand Brasil, 2006. p. 101-125.

FERREIRA, Marcos César; FERREIRA, Marta Felicia Marujo. Metodologia para Construção de Cartas-Imagem Históricas, em SIG, a partir de Imagens Digitais e Cartas Antigas: a Folha Topográfica de Jaboticabal, de 1927 (São Paulo, Brasil). In: SIMPÓSIO LUSOBRASILEIRO DE CARTOGRAFIA HISTÓRICA, 4, 2011, Porto. Anais... Porto: 2011.

FERREIRA, Mario Clemente. O Mapa das Cortes e o Tratado de Madrid: a cartografia a serviço da diplomacia. Varia Historia, Belo Horizonte, v. 23, n. 37, p. 51-69, jan./jun. 2007.

FONSECA, Cláudia Damasceno. Retóricas cartográficas: as vilas e seus territórios nas Minas setecentistas. In: $3^{\circ}$ SIMPÓSIO IBEROAMERICANO DE HISTÓRIA DA CARTOGRAFIA Agendas para História da Cartografia Iberoamericana, 2010, São Paulo. Disponível: $<$ http://3siahc.files.wordpress.com/2010/04/claudia-damasceno-3siach-2010.pdf >. Acesso em: 6 ago. 2013.

FONSECA, Fernanda Padovesi et al. Cartografia digital geo-histórica: uma avaliação da mobilidade urbana de São Paulo no final do século XIX e início do século XX. Revista do Instituto de Estudos Brasileiros, São Paulo, n. 64, p. 131-166, ago. 2016.

FURTADO, Júnia Ferreira. Um cartógrafo rebelde? José Joaquim da Rocha e a cartografia de Minas Gerais. Anais do Museu Paulista, São Paulo, v. 17, n. 2, p. 155-187, jul./dez. 2009.

Guerra, diplomacia e mapas: a Guerra da Sucessão Espanhola, o Tratado de Utrecht e a América portuguesa na cartografia de D'Anville. Topoi, v. 12, n. 23, p. 66-83, jul./dez. 2011.

GARCIA, João Carlos; KANTOR, Iris. Comércio e consumo de mapas no império português, século XVIII e XIX. In: SIMPÓSIO NACIONAL DE HISTÓRIA (ANPUH), 26, 2011, São Paulo. Anais... São Paulo: ANPUH, 2011.

GIRARDI, Giseli. Leituras de mitos em mapas: um caminho para repensar as relações entre geografia e cartografia. GEOGRAFARES, Vitória, v. 1, n. 1, p. 41-50, jun. 2000. Disponível em: <http://www.periodicos.ufes.br/geografares/article/download/1162/874>. Acesso em: 27 set. 2015.

GOMES, Maria do Carmo Andrade. Velhos mapas, novas leituras: revisitando a história da cartografia. GEOUSP - Espaço e Tempo, São Paulo, n. 16, p. 67-79, 2004. Disponível em: $<$ http://www.geografia.fflch.usp.br/publicacoes/Geousp/Geousp16/Artigo4.pdf>. Acesso em: 20 ago. 2015.

GOOGLE EARTH. Disponível em: <http://www.google.com/earth/>. Acesso em: 25 jun. 2014. 
GOOGLE MAPS. Disponível em: <https://www.google.com/maps/>. Acesso em: 25 jun. 2014.

HARLEY, John Brian. Maps, Knowledge and Power. In: COSGROVE, Denis; DANIELS, Stephen (Orgs.). The Iconography of Landscape. Cambridge: Cambridge University Press, 1988. p. 277-312.

Deconstructing the Map. Cartographica, v. 26, n. 2, p. 1-20, 1989.

KANTOR, Iris. Mapas em trânsito: projeções cartográficas e processo de emancipação política do Brasil (1779-1822). Araucaria Revista Iberoamericana de Filosofía, Política y Humanidades, ano 12 , n. 24, p. 110-123, 2010.

Cartografia e diplomacia: usos geopolíticos da informação toponímica (1750-1850). Anais do Museu Paulista, São Paulo, v. 17, n. 2, p. 39-61, jul./dez. 2009. Disponível em: <http://www.scielo.br/pdf/anaismp/v17n2/04.pdf>. Acesso em: 6 ago. 2013.

et al. Novo espaço para a cartografia histórica. Revista do Arquivo Público Mineiro, Belo Horizonte, ano XLVII, n. 1, p. 133-140, jan./jun. 2011. Disponível em: <http://www. siaapm.cultura.mg.gov.br/acervo/rapm_pdf/2011E04.pdf>. Acesso em: 6 ago. 2013.

KNOWLES, Anne Kelly. GIS and History. In: ; HILLIER, Amy (Orgs.). Placing History: How Maps, Spatial Data, and GIS are Changing Historical Scholarship. Redlands: ESRI Press, 2008. p. $1-25$.

LABORATÓRIO DE HISTÓRIA SOCIAL DA UNIVERSIDADE DE BRASÍLIA. Atlas digital da América Lusa. Disponível em: <http://lhs.unb.br/biblioatlas/Início>. Acesso em: 26 jun. 2014.

LADURIE, Emmanuel Le Roy. O historiador e o computador. In: NOVAIS, Fernando; SILVA, Rogerio Forastieri (Orgs.). Nova história em perspectiva. São Paulo: Cosac Naify, 2011. p. 206-210. v. 1.

LE GOFF, Jacques (Org.). A história nova. São Paulo: Martins Fontes, 2005.

A história nova. In: NOVAIS, Fernando; SILVA, Rogerio Forastieri (Orgs.). Nova história em perspectiva. São Paulo: Cosac Naify, 2011, p. 128-176. v. 1.

MENESES, Ulpiano Bezerra de. Do teatro da memória ao laboratório da História: a exposição museológica e o conhecimento histórico. Anais do Museu Paulista, São Paulo, N. Ser., v. 2, p. 9-42, jan./dez. 1994 .

A fotografia como documento - Robert Capa e o miliciano abatido na Espanha: sugestões para um estudo histórico. Tempo, Rio de Janeiro, n. 14, p. 131-151, 2002.

Fontes visuais, cultura visual, História visual. Balanço provisório, propostas cautelares. Revista Brasileira de História, São Paulo, v. 23, n. 45, p. 11-36, 2003.

MORAES, Antonio Carlos Robert. Ideologias geográficas. São Paulo: Hucitec; Annablume, 2002.

NEW YORK PUBLIC LIBRARY. NYPL Map Warper. Disponível em: <http://maps.nypl.org/ warper/>. Acesso em: 24 jun. 2014. 
NIELSON, Rex P. The Unmappable Sertão. Portuguese Studies, v. 30, n. 1, p. 5-20, 2014.

NOVAIS, Fernando; SILVA, Rogerio Forastieri (Orgs.). Nova história em perspectiva. São Paulo: Cosac Naify, 2011. v. 1.

OLIVA, Jaime Tadeu et al. Apresentação do dossiê - Um perfil geo-histórico de São Paulo e de Lyon (França) do final do século XIX até 1930. Revista do Instituto de Estudos Brasileiros, São Paulo, n. 64, p. 17-19, ago. 2016.

OLIVEIRA, Thiago Kramer de. Descontruindo mapas, revelando espacializações: reflexões sobre o uso da cartografia em estudos sobre o Brasil colonial. Revista Brasileira de História, São Paulo, v. 34, n. 68, p. 151-174, 2014.

REIS FILHO, Nestor Goulart. Evolução Urbana do Brasil (1500-1720). São Paulo: Livraria Pioneira, 1968.

SIEBERT, Loren. Using GIS to document, visualize, and interpret Tokyo's spatial history. Social Science History, 24(3), p. 537-574, fall 2000. Disponível em: <http://www.ankeqiang.org/M1M2/M2_Carto/Carto_Readings/Siebert_Tokyo.pdf>. Acesso em: 1º jul. 2014.

THOMAS, Werner et al. (Orgs.). Um mundo sobre papel: livros, gravuras e impressos flamengos nos impérios português e espanhol (séculos XVI-XVII). São Paulo: Editora da Universidade de São Paulo, 2014.

VARGAS, Héctor Mendoza; GARCIA, João Carlos. A história da cartografia nos países iberoamericanos. Terra Brasilis [online], v.7-8-9, p. 2-13, 2007. Disponível em: <http://terrabrasilis. revues.org/235>. Acesso em: 16 ago. 2014.

Artigo apresentado em 28/03/2016. Aprovado em 28/12/2016. 